\title{
DISPONIBILIDADE DE FÓSFORO EM SOLOS CULTIVADOS COM ARROZ IRRIGADO POR ALAGAMENTO NO RIO GRANDE DO SUL ${ }^{(1)}$
}

\author{
Gustavo Krüger Gonçalves ${ }^{(2)} \&$ Egon José Meurer ${ }^{(3)}$
}

\begin{abstract}
RESUMO
Nos solos cultivados com arroz irrigado por alagamento no Estado do Rio Grande do Sul, a maior fração do $P$ inorgânico está ligada a óxidos de Fe. Espera-se que um extrator que tenha a capacidade de extrair o $P$ adsorvido a estes óxidos possa ser mais eficiente para avaliar a disponibilidade de $\mathbf{P}$ para as plantas de arroz. Considerando o exposto, realizou-se um experimento, em casa de vegetação, com amostras de cinco solos do Rio Grande do Sul com o objetivo de avaliar a disponibilidade de $P$ no solo para o arroz. Foram testados os seguintes métodos: Mehlich-1, Mehlich-3, resina de troca aniônica em lâminas, Olsen e P-oxalato a pH 6. Os solos foram previamente incubados com três doses de $\mathbf{P}$ na forma de superfosfato triplo e, posteriormente, cultivados com arroz, em condições reduzidas, durante 38 dias. Os coeficientes de determinação obtidos entre $o \mathrm{P}$ acumulado pelas plantas de arroz e o $\mathrm{P}$ extraído dos solos foram: $0,83 *$ para o Mehlich-1, 0,81* para o Mehlich-3, 0,88* para a resina de troca, $0,85 *$ para o Olsen e $0,59 *$ para o P-oxalato. A separação dos solos em dois grupos segundo o material de origem e os teores de óxidos de Fe de baixa cristalinidade, extraídos com oxalato a pH 6 , resultou em melhor eficiência dos métodos testados para avaliar a disponibilidade do $\mathbf{P}$ para o arroz.
\end{abstract}

Termos de indexação: fósforo disponível, solos reduzidos, métodos de extração.

\footnotetext{
(1) Trabalho apresentado no XXXI Congresso Brasileiro de Ciência do Solo, 2007 (Gramado, RS)

(2) Doutorando do Programa de Pós-graduação em Ciência do Solo - UFRGS. Bolsista da CAPES. E-mail: gutosolos@ibest.com.br

(3) Professor Associado do Departamento de Solos da UFRGS. Bolsista do CNPq. E-mail: egon.meurer@ufrgs.br
} 


\title{
SUMMARY: PHOSPHORUS AVAILABILITY IN SOILS WITH FLOODED RICE IN RIO GRANDE DO SUL, BRAZIL
}

\begin{abstract}
In the paddy rice soils in the of Rio Grande do Sul State, Brazil, most inorganic P is bound to Fe oxides. It is expected that an extractant that has the capacity to extract $P$ adsorbed to these oxides would be more efficient to evaluate the availabil-ity to rice plants. A study was carried out in a greenhouse, with five soils samples from the State of Rio Grande do Sul, to evaluate $P$ availability to rice, extracted by the following methods: Mehlich-1, Mehlich-3, anion exchange resin, Olsen and P-oxalate. The soils were first incubated with three doses of triple superphosphate and then planted with rice, in under anaerobic conditions, during 38 days. The determination coefficient between $P$ uptake by rice plants and soil-extracted $P$ was: $0.83^{*}$ for Mehlich-1, $0.81 *$ for Mehlich-3, $0.88^{*}$ for anion exchange resin, $0.85^{*}$ for Olsen and $0.59^{*}$ for $P$-oxalate. The efficiency of the tested methods to evaluate the availability of $P$ to rice was improved by the separation of soils in two groups, according to the origin and contents of low-crystalline Fe oxides, extracted with oxalate at $\mathrm{pH} 6$.
\end{abstract}

Index terms: available phosphorus, anaerobic soils, extraction methods.

\section{INTRODUÇÃO}

O extrator Mehlich-1 e a resina de troca aniônica são os mais utilizados pelos laboratórios de análises de solos do Brasil para avaliar a disponibilidade de $\mathrm{P}$ para a cultura de arroz irrigado por alagamento. $\mathrm{O}$ extrator Mehlich-1 (Nelson et al., 1953) é um extrator ácido que solubiliza frações de fosfatos de $\mathrm{Ca}$ e de $\mathrm{Al}$ e de Fe (Bahia Filho et al., 1983) e a resina, por troca iônica, adsorve o P da solução do solo, originando um gradiente entre o $\mathrm{P}$ adsorvido à resina e o da solução (Miola et al., 1995).

Há resultados contraditórios sobre o extrator mais adequado para avaliar a disponibilidade de $\mathrm{P}$ para a cultura do arroz irrigado. Em solos reduzidos, os métodos não apresentam a mesma eficiência, quando utilizados em solos oxidados (Chang, 1978). Isso é devido ao aumento dos teores de P na solução, sobretudo, pela redução do $\mathrm{Fe}^{3+}$ a $\mathrm{Fe}^{2+}$ com o alagamento, confirma as características mineralógicas, químicas e eletroquímicas de cada tipo de solo (Ponnamperuma, 1972). Grande et al. (1986) obtiveram alta correlação com o método da resina de troca aniônica e baixa correlação com o extrator Mehlich-1 em solos de várzeas localizados no Estado de Minas Gerais, enquanto Silva (1996) não constatou diferenças entre estes extratores em solos do Rio Grande do Sul.

Estes resultados indicam que os métodos usados atualmente não estimam adequadamente a capacidade de os solos fornecerem $\mathrm{P}$ à cultura do arroz em condições reduzidas (Shahandeh et al., 1994). Isto pode ser devido à inabilidade dos métodos em extrair o $\mathrm{P}$ retido nos óxidos de $\mathrm{Fe}$ de baixa cristalinidade, uma vez que estas formas são preferencialmente utilizadas pelas bactérias anaeróbias, tendo, assim, efeito significante na disponibilidade de $\mathrm{P}$ com a redução no solo (Munch \& Ottow, 1980).

A recomendação para a adubação fosfatada da cultura do arroz em solos do Rio Grande do Sul foi obtida em estudos de calibração em experimentos de campo, realizados entre as décadas de 60 e 70, em solos derivados de arenito, siltito e granito, pertencentes à classe dos Planossolos. Esses experimentos proporcionaram a obtenção do nível crítico de $6 \mathrm{mg} \mathrm{dm}^{-3}$ de $\mathrm{P}$ no solo para a cultura do arroz, ocorrendo, a partir desta época, uma generalização para todos os solos enquadrados na classe 5 (solos alagados) no sistema de recomendações de adubação e de calagem para os Estados do Rio Grande do Sul e de Santa Catarina (SBCS, 2004). Entretanto, a expansão da área cultivada com arroz irrigado para outras regiões agrícolas do Estado do Rio Grande do Sul, como as localizadas na Fronteira Oeste, possibilitou a utilização de solos oriundos de sedimento basáltico. Estes solos têm características mineralógicas, químicas e eletroquímicas diferentes das dos Planossolos o que influi na disponibilidade de $\mathrm{P}$ para a cultura. Sousa (2001) observou, num Plintossolo oriundo de sedimento de basalto, que a redução de Mn e de $\mathrm{Fe}$ foi mais lenta do que num Planossolo oriundo de sedimento de granito. Resultados semelhantes foram observados por Gonçalves (2003) que constatou, num Cambissolo oriundo de sedimento de basalto, solubilização diferenciada de $\mathrm{P}$ em relação a um Planossolo.

Este trabalho partiu da hipótese de que a separação dos solos com base no seu material de origem deve melhorar a predição da disponibilidade de $\mathrm{P}$ para a cultura do arroz irrigado, pelos extratores mais utilizados atualmente. 


\section{MATERIAL E MÉTODOS}

Realizou-se um experimento em vasos, na casade-vegetação do Departamento de Solos da Faculdade de Agronomia da UFRGS, no período de outubro a novembro de 2005 , utilizando amostras dos seguintes solos coletados no Estado do Rio Grande do Sul: 1) Planossolo Hidromórfico eutrófico solódico, coletado no município de Pelotas; 2) Gleissolo Háplico Ta distrófico, coletado no município de Cachoeirinha; 3) Luvissolo Crômico pálico abrúptico, coletado no município de Itaqui; 4) Vertissolo Ebânico órtico típico, coletado no município de Alegrete, e 5) Chernossolo Ebânico carbonático vértico, coletado no município de Alegrete (Quadro 1). A determinação das formas dos óxidos de Fe foi feita segundo o método de Mehra \& Jackson (1960) e Schwertmann (1964).

As amostras da camada superficial dos solos (0-20 $\mathrm{cm}$ ) foram expostas ao ar, destorroadas e passadas em peneira de $1 \mathrm{~cm}$ de malha, sendo, posteriormente, colocadas em vasos plásticos de $3 \mathrm{dm}^{3}$, na quantidade de $2,5 \mathrm{~kg}$ de solo seco por vaso (unidade experimental). Adicionou-se aos vasos superfosfato triplo moído e passado em peneira de $0,297 \mathrm{~mm}$, para uniformizar o tamanho das partículas, nas doses de 0, 19,6 e 39,3 $\mathrm{mg} \mathrm{kg}^{-1}$ de $\mathrm{P}$ no solo, deixando-se incubar por 30 dias. Após este período, foram retirados $50 \mathrm{~g}$ de solo de cada vaso para análises químicas para determinação de $\mathrm{P}$ disponível. A seguir, foram colocadas para germinar oito sementes de arroz por vaso, cultivar IRGA 417, e foi feito o desbaste para três plantas por vaso, quando estas apresentavam três folhas, ocasião em que se aplicou $\mathrm{N}$ na dose de $30 \mathrm{mg} \mathrm{kg}^{-1}$ de solo usando uréia dissolvida em água destilada. Logo após, os vasos foram alagados com água destilada, mantendo-se uma lâmina de água de $5 \mathrm{~cm}$ de altura durante 38 dias. Após este período, a parte aérea das plantas foi coletada a um $\mathrm{cm}$ da superfície do solo, sendo o material seco em estufa à temperatura de $65{ }^{\circ} \mathrm{C}$, por $72 \mathrm{~h}$. Após a pesagem do material para avaliar a produção de matéria seca, o tecido foi moído e nele foram determinadas as concentrações de $\mathrm{P}$ por meio do método descrito por Tedesco et al. (1995). O P nas amostras de solo foi extraído por Mehlich-1 (Nelson et al., 1953), por resina de troca aniônica em lâminas (conforme descrito em Tedesco et al., 1995), Mehlich-3 (Mehlich, 1984), Olsen (Olsen et al., 1954) e oxalato (Shahandeh et al., 1994). O teor de P nos extratos foi determinado pela adição de solução redutora de molibdato de amônio e ácido ascórbico (Murphy \& Riley, 1962), sendo feita a leitura da absorbância em espectrofotômetro de absorção a $882 \mathrm{~nm}$.

$\mathrm{O}$ experimento foi instalado em delineamento de blocos ao acaso com três repetições. $\mathrm{O}$ teor de $\mathrm{P}$ extraído pelos extratores foi relacionado com o $\mathrm{P}$ acumulado pelas plantas de arroz, utilizando Sistema de Análise Estatística para Microcomputadores SANEST (Zonta et al., 1984)

\section{RESULTADOS E DISCUSSÃO}

Os teores de P extraídos pelos cinco extratores foram diferentes. Pelo extrator de Mehlich-1, variaram de 2,8 a $18,9 \mathrm{mg} \mathrm{kg}^{-1}$ de $\mathrm{P}$ no solo; para a resina de 1,6 a $11,1 \mathrm{mg} \mathrm{kg}^{-1}$ de $\mathrm{P}$; para Mehlich-3 de 1,9 a $12,9 \mathrm{mg} \mathrm{kg}^{-1}$ de $\mathrm{P}$; para o método de Olsen de 7,5 a $35,8 \mathrm{mg} \mathrm{kg}^{-1}$ de $\mathrm{P}$ e por oxalato de $15,2 \mathrm{a}$ $71,9 \mathrm{mg} \mathrm{kg}{ }^{-1}$ de $\mathrm{P}$ no solo. A resina e o Mehlich-3 extraíram teores similares de $\mathrm{P}$ dos solos. Os métodos de Olsen e do oxalato extraíram teores maiores de $\mathrm{P}$ que os anteriores. Na extração com oxalato, o P extraído na maior dose de $\mathrm{P}$ aplicada $\left(39,3 \mathrm{mg} \mathrm{kg}^{-1}\right.$ de $\mathrm{P}$ no solo) atingiu 71,9 $\mathrm{mg} \mathrm{kg}^{-1}$ no $\mathrm{P}$ no solo.

Quadro 1. Atributos das amostras dos solos utilizados no experimento

\begin{tabular}{|c|c|c|c|c|c|c|c|c|c|c|}
\hline $\begin{array}{l}\text { Classificação } \\
\text { taxonômica }\end{array}$ & $\begin{array}{c}\text { Material } \\
\text { de origem }\end{array}$ & Argila & M.O. & $\begin{array}{c}\mathbf{p H} \\
\mathbf{H}_{2} \mathrm{O}\end{array}$ & $\begin{array}{l}\text { Índice } \\
\text { SMP }\end{array}$ & $\mathbf{K}$ & $\mathbf{P}$ & $\begin{array}{l}\text { Saturação } \\
\mathrm{Al}\end{array}$ & $\mathrm{FeO}_{6}{ }^{(1)}$ & Fed $^{(2)}$ \\
\hline & & \multicolumn{2}{|c|}{$\mathrm{g} \mathrm{kg}^{-1}$} & & & \multicolumn{2}{|c|}{$\mathrm{mg} \mathrm{kg}^{-1}-$} & $\%$ & \multicolumn{2}{|c|}{$\mathrm{g} \mathrm{kg}^{-1}$} \\
\hline $\begin{array}{l}\text { Planossolo Hidromórfico } \\
\text { eutrófico solódico }\end{array}$ & $\begin{array}{l}\text { Sedimentos } \\
\text { de granito }\end{array}$ & 200 & 21 & 4,7 & 6,2 & 61 & 3,0 & 8,9 & 0,40 & 5,62 \\
\hline $\begin{array}{l}\text { Gleissolo Háplico Ta } \\
\text { distrófico }\end{array}$ & $\begin{array}{l}\text { Sedimentos } \\
\text { de granito }\end{array}$ & 220 & 22 & 4,4 & 5,8 & 85 & 5,5 & 17,7 & 0,28 & 4,80 \\
\hline $\begin{array}{l}\text { Luvissolo Crômico } \\
\text { pálico abrúptico }\end{array}$ & Basalto & 230 & 17 & 4,3 & 5,5 & 80 & 2,5 & 13,5 & 0,90 & 7,90 \\
\hline $\begin{array}{l}\text { Vertissolo Ebânico } \\
\text { órtico típico }\end{array}$ & Basalto & 320 & 40 & 5,5 & 5,9 & 102 & 2,9 & 0,0 & 1,45 & 10,85 \\
\hline $\begin{array}{l}\text { Chernossolo Ebânico } \\
\text { carbonático vértico }\end{array}$ & Basalto & 280 & 27 & 4,9 & 6,0 & 114 & 2,7 & 3,1 & 1,58 & 11,02 \\
\hline
\end{tabular}

(1) Extração com oxalato de amônio a pH 6; (2) extração com ditionito-citrato-bicarbonato 
Estes resultados podem ser atribuídos aos princípios de extração de cada método. Ácidos fortes diluídos, como o extrator de Mehlich-1, mantêm a atividade de $\mathrm{H}^{+}$na solução suficiente para dissolução parcial de fosfatos de $\mathrm{Ca}, \mathrm{Fe}$ e $\mathrm{Al}$ (Lindsay, 1979). Ácidos fortes diluídos como o de Mehlich-3 (Mehlich, 1984), baseiam-se na dissolução ácida na presença de complexantes. Soluções alcalinas tamponadas, como o extrator Olsen, quando usadas em solos ácidos ou neutros, por causa das concentrações de $\mathrm{OH}^{-}$diminui a atividade de $\mathrm{Al}^{3+}$ pela formação do complexo aluminato e de $\mathrm{Fe}^{3+}$ pela precipitação como óxido de $\mathrm{Fe}$, favorecendo, desta forma, a solubilidade de $\mathrm{P}$ de $\mathrm{Al}$ e de $\mathrm{Fe}$. Além disso, o aumento do $\mathrm{pH}$ na solução gera novas cargas negativas na superfície das partículas, favorecendo a dessorção de $\mathrm{P}$. O extrator P-oxalato $\left[\left(\mathrm{NH}_{4}\right)_{2} \mathrm{C}_{2} \mathrm{O}_{4} \cdot \mathrm{H}_{2} \mathrm{O}+\mathrm{H}_{2} \mathrm{C}_{2} \mathrm{O}_{4} 0,2\right.$ mol L-1)] proposto por Shahandeh et al. (1994) dissolve óxidos de $\mathrm{Fe}$ pouco cristalinos, liberando $\mathrm{P}$ para a solução do solo. O método de extração de $\mathrm{P}$ por resinas trocadoras de íons foi proposto inicialmente por Amer et al. (1955). Ele se baseia na adsorção da solução pela resina e sua posterior dessorção da fase sólida para estabelecer novo equilíbrio entre as fases (sólida e líquida) do solo. Nesse caso, a resina é adequada para estimar a capacidade de suprimento, pois o processo de extração assemelha-se à ação das raízes das plantas (Vaidyanathan \& Talibudeen, 1970).

O método Mehlich-3 extraiu menos $\mathrm{P}$ do solo do que o Mehlich-1, o que contradiz resultados obtidos por Sims (1989) e Kroth (1998). Segundo esses autores, a presença do $\mathrm{F}^{-}$neste método extrai preferencialmente o $\mathrm{P}$ ligado ao $\mathrm{Al}$ formando um complexo Al-F e os agentes complexantes contribuem significativamente para que não ocorra readsorção de $\mathrm{P}$ pelo solo, o que aumenta o teor de $\mathrm{P}$ extraído. Os menores teores de $\mathrm{P}$ extraídos pelo Mehlich 3 em relação Mehlich 1, observados neste trabalho, podem ser atribuídos à baixa saturação por $\mathrm{Al}^{3+}$ do Planossolo, Vertissolo e Chernossolo (Quadro 1).

Dentre os cinco métodos testados, a resina de troca aniônica foi a mais eficiente para avaliar a disponibilidade do $\mathrm{P}\left(\mathrm{R}^{2}=0,88\right.$, Figura 2$)$, quando foram utilizadas amostras de todos os solos. Grande et al. (1986) relataram que a eficiência da resina deve estar associada ao pH de equilíbrio, entre 6,5 e 7,0, de seu extrato. Este pH coincide com aquele predominante nos solos reduzidos do Rio Grande do Sul, condições em que se desenvolve a cultura do arroz, diferente das encontradas nas amostras secas, analisadas nos laboratórios nas quais geralmente o $\mathrm{pH}$ é menor, o que não favorece a extração de $\mathrm{P}$ ligado aos óxidos de $\mathrm{Fe}$, formas predominantes em solos alagados.
A relação entre a quantidade de $\mathrm{P}$ acumulada nas plantas de arroz e o teor de P extraído dos solos pelos cinco extratores foi significativa (Figuras 1, 2 e 3). O maior coeficiente de determinação foi obtido para a resina trocadora de ânions $\left(\mathrm{R}^{2}=0,88^{*}\right)$ seguido por Olsen $\left(R^{2}=0,85^{*}\right)$ por Mehlich-1 $\left(R^{2}=0,83^{*}\right)$ e Mehlich$3\left(R^{2}=0,81^{*}\right)$. O extrator que se mostrou menos eficiente foi do oxalato $\left(R^{2}=0,59^{*}\right)$. Com exceção do oxalato, de maneira geral, os métodos mostraram-se eficazes para avaliar a disponibilidade de $\mathrm{P}$ para o arroz, apresentando os teores de P extraídos pelos diferentes métodos correlação significativa entre si (Quadro 2).
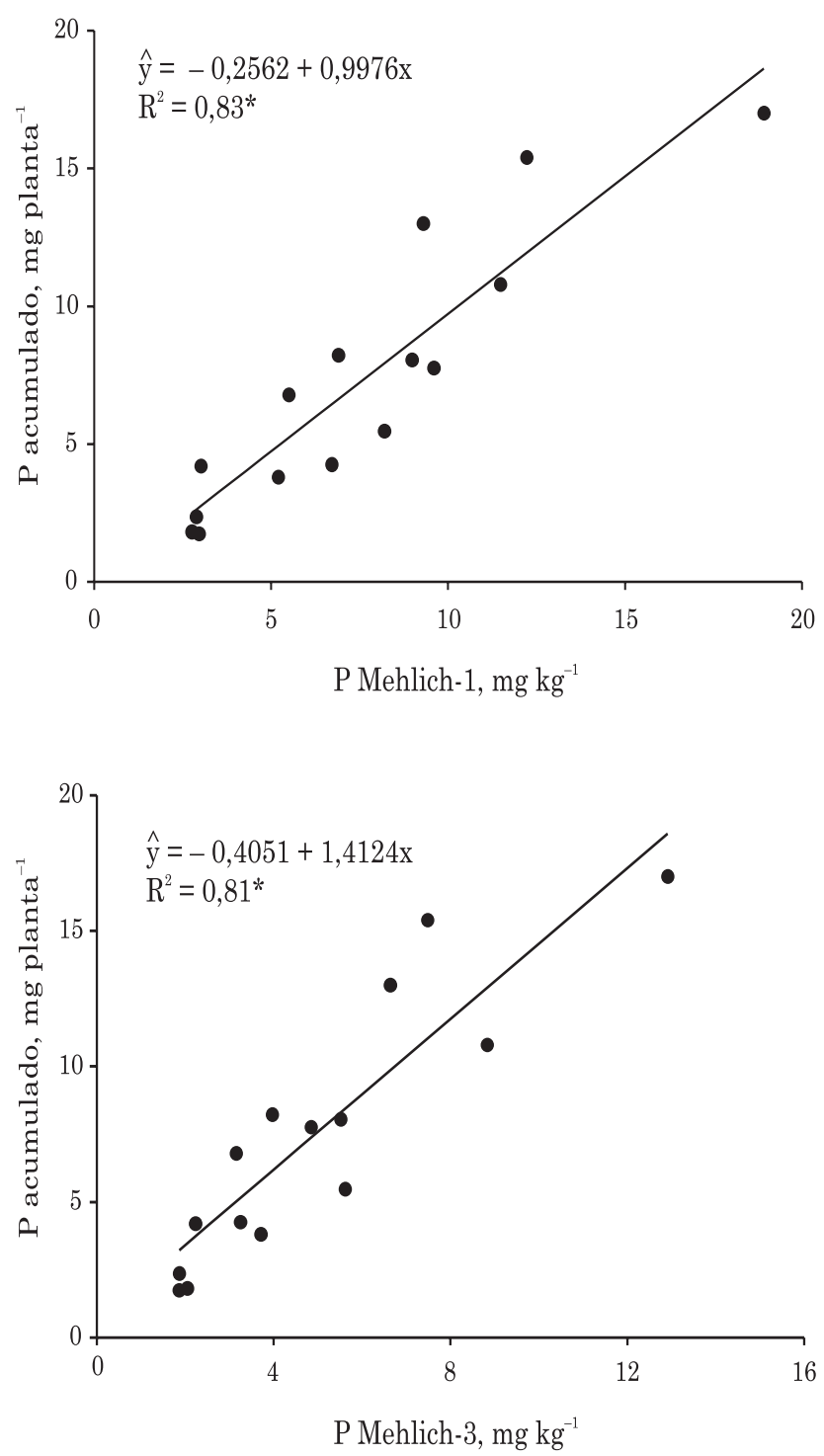

Figura 1. Relação entre os teores de fósforo extraídos pelo Mehlich-1 e Mehlich-3 e as quantidades de fósforo acumulado pelo arroz nas amostras dos solos: Planossolo, Gleissolo, Luvissolo, Vertissolo e Chernossolo, nas três doses de fósforo $(0 ; 19,65$ e $39,3 \mathrm{mg} \mathrm{kg}^{-1}$ de $\mathrm{P}$ no solo). 


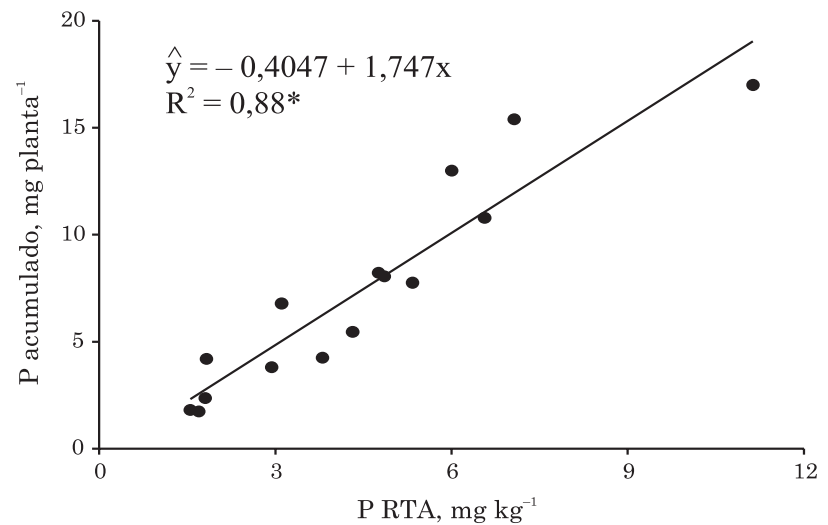

Quadro2. Coeficiente de correlação linear (r) entre os métodos de extração de fósforo do solo

\begin{tabular}{lccccc}
\hline & Mehlich-1 & Mehlich-3 & Resina & Olsen & P-oxalato \\
\hline Mehlich-1 & - & $0,97^{* *}$ & $0,99^{* *}$ & $0,92^{* *}$ & $0,84^{* *}$ \\
Mehlich-3 & $0,97^{* *}$ & - & $0,97^{* *}$ & $0,89^{* *}$ & $0,79^{*}$ \\
Resina & $0,99^{* *}$ & $0,97^{* *}$ & - & $0,95^{* *}$ & $0,86^{* *}$ \\
Olsen & $0,92^{* *}$ & $0,89^{* *}$ & $0,95^{* *}$ & - & $0,94^{* *}$ \\
\hline
\end{tabular}

*Significativo a $5 \%$; ** significativo a $1 \%$.

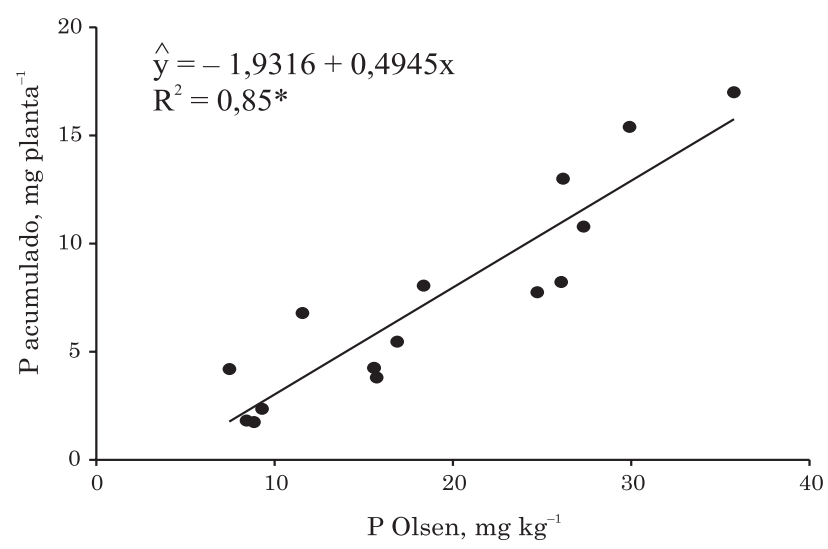

Figura 2. Relação entre os teores de fósforo extraídos pela resina de troca aniônica (RTA) e Olsen e as quantidades de fósforo acumulado pelo arroz nas amostras dos solos: Planossolo, Gleissolo, Luvissolo, Vertissolo e Chernossolo, nas três doses de fósforo $\left(0 ; 19,6\right.$ e $39,3 \mathrm{mg} \mathrm{kg}^{-1}$ de $\mathrm{P}$ no solo).

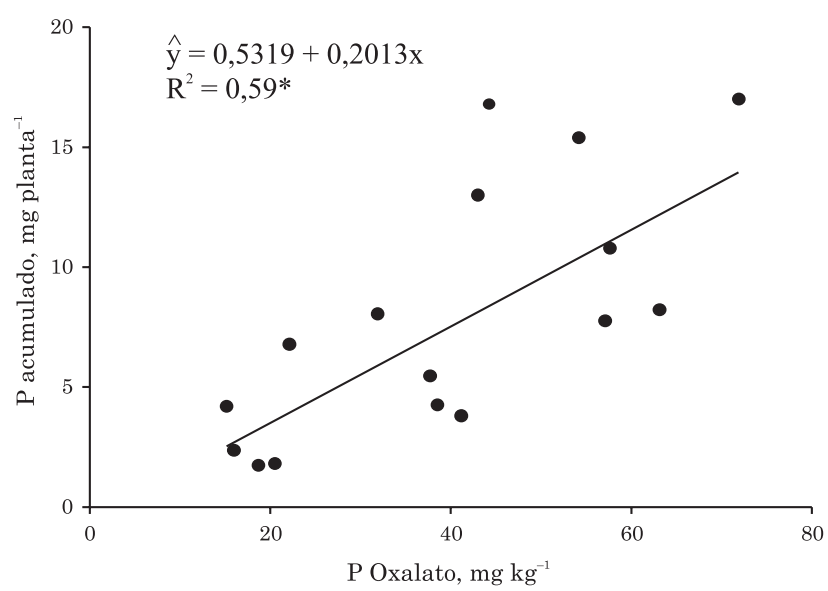

Figura 3. Relação entre os teores de fósforo extraídos por oxalato e as quantidades de fósforo acumulado pelo arroz nas amostras dos solos: Planossolo, Gleissolo, Luvissolo, Vertissolo e Chernossolo, nas três doses de fósforo $(0 ; 19,6 \mathrm{e}$ $39,3 \mathrm{mg} \mathrm{kg}^{-1}$ de $\mathrm{P}$ solo).

A separação dos solos em dois grupos, segundo o seu material de origem e os teores óxidos de Fe mal cristalizados, aumentou a eficiência dos métodos para avaliar a disponibilidade de P (Quadro 3). Os solos do grupo 1 (Planossolo e Gleissolo), representado pelos dois solos originados de granito, e os do grupo 2 (Luvissolo, Vertissolo e Chernossolo), representado pelos solos derivados do basalto, apresentaram maiores coeficientes de determinação, indicando que a separação dos solos melhorou a avaliação da disponibilidade de P. Para os solos de origem granítica, os métodos mais eficientes foram os de Olsen e P-oxalato e para os de origem basáltica foram a resina e o de Olsen. Os óxidos de Fe de baixa cristalinidade extraídos a pH 6, que estão em maiores teores nos solos derivados do basalto (Quadro 1), podem ser indicadores de aumento da dispo-nibilidade de $\mathrm{P}$ com a redução no solo. Essas formas químicas de Fe são substrato para bactérias anaeróbias durante a redução de óxido férrico a ferroso, aumentando a solubilidade do $\mathrm{Fe}^{2+}$ e, indiretamente, os teores de P na solução (Munch \& Ottow, 1980).

Quadro 3. Coeficiente de determinação entre os teores de fósforo extraídos dos solos e o fósforo acumulado pelas plantas de arroz, para todos os solos num único grupo (geral) e separados de acordo com os teores de ferro de baixa cristalinidade (extração com oxalato a pH 6).

\begin{tabular}{lccc}
\hline \multirow{2}{*}{ Método } & \multicolumn{3}{c}{ Grupo de solo(1) $^{(1)}$} \\
\cline { 2 - 4 } & Geral & $\mathbf{1}$ & $\mathbf{2}$ \\
\hline Mehlich-1 & $0,83^{*}$ & $0,84^{*}$ & $0,86^{*}$ \\
Mehlich-3 & $0,81^{*}$ & $0,83^{*}$ & $0,79^{*}$ \\
Resina & $0,88^{*}$ & $0,88^{*}$ & $0,95^{*}$ \\
Olsen & $0,85^{*}$ & $0,98^{*}$ & $0,95^{*}$ \\
P-oxalato & $0,59^{*}$ & $0,95^{*}$ & $0,85^{*}$ \\
\hline
\end{tabular}

(1) Grupo 1 = Planossolo e Gleissolo; Grupo 2 = Luvissolo, Vertissolo e Chernossolo.

* Significativo a $5 \%$ de probabilidade.

Os resultados obtidos indicam que o material de origem e os teores e formas dos óxidos de Fe podem 
alterar a disponibilidade de $\mathrm{P}$ para a cultura de arroz irrigado por alagamento em solos do Rio Grande do Sul. Isto mostra que estes solos necessitam de interpretação diferenciada para o $\mathrm{P}$ extraído, desde que é possível que existam níveis críticos diferentes para solos oriundos de sedimento de basalto e granito.

\section{CONCLUSÕES}

1. O teor de $\mathrm{P}$ extraído dos solos pelos métodos testados apresentou correlação significativa com o $\mathrm{P}$ acumulado nas plantas de arroz. A resina de troca aniônica foi a mais eficiente para avaliar a disponibilidade de $\mathrm{P}$, seguida pelos métodos de Olsen, Mehlich-1, Mehlich-3 e P-Oxalato.

2. A separação dos solos em grupos, segundo o material de origem e os teores de óxidos de Fe de baixa cristalinidade extraídos com oxalato a $\mathrm{pH} 6$, resultou em melhor eficiência de todos os métodos testados para avaliar a disponibilidade de $\mathrm{P}$ para o arroz.

\section{LITERATURA CITADA}

AMER, F.; BOULDIN, D.R.; BLACK, C.A.; DUKE, F.R Characterization of soil phosphorus by anion exchange resin adsorption and $\mathrm{P}^{32}$ equilibration. Pl. Soil, v.6: 391-408, 1955.

BAHIA FILHO, A.F.C.; BRAGA, J.M.; RESENDE, M. \& RIBEIRO, A.C. Relação entre adsorção de fósforo e componentes mineralógicos da fração argila de Latossolos do Planalto Central. R. Bras. Ci. Solo, 7:221-226, 1983.

CHANG, S.C. Evaluation of the fertility of rice soils. In: INTERNATIONAL RICE RESEARCH INSTITUTE. Soils \& Rice. Los Baños, 1978. p. 521-542.

GONÇALVES, G.K. Disponibilidade de fósforo em solos reduzidos. Porto Alegre, Universidade Federal do Rio Grande do Sul, 2007. 188p. (Tese de Doutorado)

GRANDE, M.A.; CURI, N. \& QUAGGIO, J.A. Disponibilidade de fósforo pelos extratores de Mehlich e resina, em solos cultivados com arroz irrigado. R. Bras. Ci. Solo, 10:45-50, 1986.

KROTH, P.L. Disponibilidade de fósforo no solo para plantas e fatores que afetam a extração por resina de troca em membrana. Porto Alegre, Universidade Federal de Porto Alegre, 1998. 168p. (Tese de Doutorado)

LINDSAY, W. Chemical equilibria in soils. New York: John Wiley \& Sons, 1979. 449p.

MEHLICH, A. Mehlich 3 soil test extractant: A modification of Mehlich 2 extractant. Comm. Soil Sci. Plant Anal., 15:14091416,1984

MEHRA, O.P. \& JACKSON, M.L. Iron oxide removal from soils and clay by a dithionite-citrate system buffered with sodium bicarbonate. In: NATIONAL CONFERENCE CLAYS \& CLAY MINERALS, 7., Ottawa, 1960. Proceedings. Ottawa, S.I.S, 1960. p.317-327.
MIOLA, G.R. Extração de P, K, Ca e Mg por diferentes métodos e avaliação da disponibilidade de fósforo para as plantas. Porto Alegre, Universidade Federal do Rio Grande do Sul, 1995. 127p. (Tese de Mestrado)

MUNCH, J.C. \& OTTOW, J.C.G. Preferential reduction of amorphous to crystalline iron oxides by bacterial activity. Soil Sci., 129:15-21, 1980.

MURPHY, J. \& RILLEY, J.P. A modified single solution method for the determination of phosphate in natural waters. Anal. Chimica Acta, 27:31-36, 1962.

NELSON, W.L.; MEHLICH, A. \& WINTERS, E. The development, evaluation, and use of soil tests for phosphorus availability. In: PIERRE, W.H. \& NORMAN, A.G., eds. Soil and fertilizer phosphorus. New York, Academic Press, 1953. v.4. p.153-188.

OLSEN, S.R.; COLE, C.V.; WATANABE, F.S. \& DEAN, L.A. Estimation of available phosphorus in soils by extraction with sodium bicarbonate. Washington, USDA, 1954. (USDA Circ., 939)

PONNAMPERUMA, F.N. The chemistry of submerged soils. Adv. Agron., 24: 29-96, 1972.

SHAHANDEH, H.; HOSSNER, R.L. \& TURNER, F.T. Phosphorus relationships in flooded rice soils with low extractable phosphorus. Soil Sci. Soc. Am. J., 58:1184-1189, 1994.

SCHWERTMANN, U. Differenzierung der eisenoxide des bodens durch extraction mit ammoniumoxalat-losung. Zeitschrift Pflanz. Bodenk., 105:194-202, 1964

SILVA, R.J.S. Metodologia de avaliação da disponibilidade de fósforo em solos alagados. Pelotas, Universidade Federal de Pelotas, 1996. 57p. (Tese de Mestrado)

SIMS, J.T. Comparison of Mehlich 1 and Mehlich 3 extractants for $\mathrm{P}, \mathrm{K}, \mathrm{Ca}, \mathrm{Mg}, \mathrm{Mn}, \mathrm{Cu}$ and $\mathrm{Zn}$ in atlantic Coastal Plain soils. Comm. Soil Sci. Plant Anal., 20:1707-1726, 1989.

SOCIEDADE BRASILEIRA DE CIÊNCIA DO SOLO - SBCS. Comissão de Química e Fertilidade do Solo. Manual de adubação e calagem para os Estados do Rio Grande do Sul e de Santa Catarina. 10.ed. Porto Alegre, 2004. 400 p.

SOUSA, R.O. Oxirredução em solos alagados afetada por resíduos vegetais. Porto Alegre, Universidade Federal do Rio Grande do Sul, 2001. 164p. (Tese de Doutorado)

TEDESCO, M.J.; VOLKWEISS, S.J. \& BOHNEN, H. Análises de solos, plantas e outros materiais. Porto Alegre, Universidade Federal do Rio Grande do Sul, 1995. 188p. (Boletim Técnico,5)

TEO, Y.H.; BEYROUTY, C.A. \& GBUR, E.E. Relating soil test $\mathrm{P}$ to $\mathrm{P}$ uptake by paddy rice. Soil Sci., 159:409-414, 1995.

VAIDYANATHAM, L.V.; TALIBUDEEN. Rate processes in the desorption of phosphate from soils by ion exchange resins. J. Soil Sci., v.21:173-183, 1970.

ZONTA, E.P.; MACHADO, A.A. \& SILVEIRA, J.P. Sistema de análise estatística para microcomputadores (SANEST). Pelotas, Universidade Federal de Pelotas, 1984. 151p. 